\title{
Compliance to Antiretroviral Medication as Reported by AIDS Patients Assisted at the University Hospital of the Federal University of Mato Grosso do Sul
}

Maria Tereza Ferreira Duenhas Monreal,
Rivaldo Venâncio da Cunha and Luzia Aparecida Trinca
Department of Food Technology and Public Health, Department of Infectious Diseases, Federal University of Mato Grosso do Sul; Department of Bio-Statistics, UNESP, Botucatu/SP, Brazil

\begin{abstract}
Compliance to antiretroviral medication is a problem for AIDS patients. Compliance can be influenced by the characteristics of the therapeutic program, by the health guidance professionals, by the patient, and by society in general. A group of 139 Brazilian AIDS patients from the Infectious-Parasitic Diseases day clinic at the University Hospital of the Federal University of Mato Grosso do Sul were interviewed from September 27, 1999 to January 21, 2000. We identified and evaluated the frequency of noncompliance to antiretroviral medication, as well as the associated motives. Those who ingested $80 \%$, or more, of prescribed dosages during the week previous to the interview were considered compliant. Among the patients interviewed, $70 \%$ mentioned loss or misplacement of medicine, and 63\% were considered compliant. Average compliance was $\mathbf{7 5 . 8} \%$, with no difference between the sexes. The reasons given for non-compliance were: absentmindedness or forgetfulness $(67.7 \%)$, lack of medicine $(41.9 \%)$, side effects $(21.5 \%)$, complexity of prescribed regimens $(12.9 \%)$, fatigue $(9.7 \%)$, and voluntary interruption $(7.5 \%)$. The noncompliance observed among these patients indicates that health service personnel should promote activities to recuperate these therapeutic programs, employing methodologies appropriate to the characteristics of this population.
\end{abstract}

Key Words: AIDS, compliance, antiretroviral.

Many studies have been made of compliance with antiretroviral treatment, as low compliance could lead to the appearance of strains resistant to the medicines, causing difficulties for the therapeutic management of patients [1]. Compliance can be influenced by the type of therapeutic regimen imposed, by the health worker or agent, by the patient, and by society [2,3]. During the last decade, with the introduction of new combinations and mixtures of medicines, the occurrence of opportunistic infections and mortality rate due to AIDS has been significantly reduced [2], but lack of compliance continues to be a problem.

Received on 12 September 2001; revised 15 February 2002.

Address for correspondence: Dr. Maria Tereza Ferreira Duenhas Monreal. Rua Salim Kahil, nº 409 Vila Nogueira, Botucatu-SP, Zip code: 18606-760, Brazil. E-mail: monreal@laser.com.br

The Brazilian Journal of Infectious Diseases 2002;6(1):8-14 (C) 2002 by The Brazilian Journal of Infectious Diseases and Contexto Publishing. All rights reserved.

1413-8670
Patient-reporting is one of the methods employed to measure compliance with a given therapeutic regimen [4-8]. This method can provide both qualitative and quantitative information [9].

Compliance can be defined in different ways. In some studies, patients that took $80 \%$ or more of the prescribed medicines in a given period were considered compliant [3-5]. We investigated the prevalence of compliance with antiretroviral therapy among patients with AIDS, who were being attended at the University Hospital of the Federal University of Mato Grosso do Sul, and the reasons for non-compliance with antiretroviral treatment among these patients.

\section{Individuals}

A descriptive-analytical transverse study was made of 139 AIDS patients, of both sexes, 19 to 65 years 
old, who appeared regularly at the day clinic of the Infectious-Parasitic Diseases unit of the University Hospital, from September 27, 1999 to January 21, 2000.

\section{Methods}

Interviews were conducted with 139 patients, using a standard questionnaire identifying: sex, age, civil status, occupation, schooling, time since HIV positive diagnosis, length of time of treatment, number of times interned because of HIV/AIDS, number of medicines used during the previous month, loss or omission of any antiretroviral medication dosage and reason for the loss or omission. The patient information regarding the antiretroviral drugs was compared to the medical prescription for each individual.

Criteria for inclusion. Individuals with AIDS, both sexes over 18 years of age, with prescriptions for antiretroviral medication, assisted at the InfectiousParasitic Diseases day-clinic and who agreed to participate in this study.

Criteria for exclusion. Individuals with AIDS that did not appear at the day-clinic during the period of the study, those who had no prescription for antiretroviral medication and those who refused to sign the terms of agreement.

Analysis of results. For this study, those individuals who took $80 \%$, or more, of medicines (pills) prescribed, during the week prior to the interview were considered compliant.

Descriptive statistics techniques were utilized for the quantitative variables, with calculations of average, median, standard deviation, minimum and maximum, and coefficient of correlation between pairs of variables - Pearson Correlation Coefficient. Tables of frequencies and percentages were prepared for qualitative variables [10-11].

This investigation was classified as being a census type study because among the 141 individuals who regularly appeared at the clinic, only two $(1.4 \%)$ did not consent to participate in the survey.

\section{Results}

Of the 139 patients interviewed, $67.6 \%$ were males; $0.7 \%$ were under 20 years of age, $19.4 \%$ were between 20 and 29, 50.4\% were between 30 and $39,21.6 \%$ were between 40 and $49,6.5 \%$ were between 50 and 59 , and $1.4 \%$ were 60 years of age or over. Only $25.9 \%$ had a steady or permanent partner.

Among the subjects with an occupation, 19.4\% were informally employed, without work contract, life insurance, or social security; $18.7 \%$ stated no job, 14.4\% said retired, $11.5 \%$ answered "general services" (presumably menial work), 11.5\% indicated commerce and auxiliary services, 9.4\% were in industry and construction, $7.9 \%$ were in technical, scientific, artistic, and similar activities; $5 \%$ were in an administrative occupation and 2.2\% worked with transportation.

With regard to schooling, $7.2 \%$ were illiterate, $47.5 \%$ had incomplete basic schooling, $11.5 \%$ had completed basic school, 7.9\% had started but not completed high school, 16.5\% had completed high school and $9.4 \%$ had attended college.

The interval since HIV positive diagnosis was 2.6 years for $44 \%$ of the patients, for $34 \%$ it was between 2.6 and 5.2 years, $18 \%$ between 5.2 and 7.8 years, $2 \%$ between 7.8 and 10.4 years and $2 \%$ between 10.4 and 13 years. For duration of treatment, $46 \%$ indicated up to 1.4 years, $29 \%$ between 1.4 and 2.8 years, $16 \%$ between 2.8 and 4.2 years, $8 \%$ between 4.2 and 5.6 years and $1 \%$ between 5.6 and 7 years.

For number of times of hospitalizations related to HIV/AIDS, $56.1 \%$ answered none, $27.3 \%$ only once, $10.1 \%$ said twice, $5 \%$ said three times, $0.7 \%$ said four times, and $0.7 \%$ said five times. The prescribed medication was utilized by $66.9 \%$ of the patients, $24.5 \%$ took lesser quantities and $8.6 \%$ used none.

Loss of doses of antiretroviral medicines during the week prior to the interviews was mentioned by $66.9 \%$ of the patients. Among the reasons offered, absent-mindedness or forgetfulness was stated by 
$67.7 \%$, lack of the drugs by $41.9 \%$, (avoidance of) side effects by $21.5 \%$, complexity of therapeutic treatment by $12.9 \%$, fatigue by $9.7 \%$ and voluntary interruption by $7.5 \%$ of the patients. Some patients indicated two motives in their justification of noncompliance.

Table 1 shows mean age (36.1 years), time since diagnosis (3.5 years), duration of treatment (2 years), number of hospitalizations ( 0.7 times), number of medicines used (2.9), of pills ingested (10.3) and compliance $(75.8 \%)$. A large range was observed for all the variables.

There was little correlation of compliance with age $(-0.06848)$, with time since diagnosis $(-0.02585)$, with duration of treatment $(0.07596)$, and with the number of hospitalizations (-0.02818). However, there was some degree of correlation with the number of drugs used (0.45895).

The profiles of the variables, age, time since diagnosis, duration of treatment, number of hospitalizations, numbers of drugs utilized, and compliance were similar for both sexes, as shown in Table 2.

Employment appeared to have no influence on compliance, since $60.6 \%$ of the patients that had an occupation were compliant, and $64.4 \%$ of those with no occupation (including the retired) were also compliant.

The group with the most schooling (high school and/ or college level) presented $85.1 \%$ compliance. The percentages of compliance and non-compliance were similar among those with less schooling. For those with complete or incomplete basic schooling, $51.2 \%$ were compliant (Table 3), while $50 \%$ of the illiterate were compliant. The percentages of compliance were the same for both sexes. Taken together, $63 \%$ were compliant (Table 4).

\section{Discussion}

In this study, the level of compliance was calculated based on information obtained directly from the patient. Though there is a risk of over-estimation, this is a simple, rapid, and low-cost method, and which can be very efficient if judged impartially, guaranteeing strict confidentiality. This direct interview method has been widely utilized [4,7,8,12-17].

The criterion for adequate compliance applied in this study was $80 \%$ or more, of the medicine (pills) ingested in the seven-day period prior to the interviews. This index has been used in many studies, independent of the methodology employed $[4,6,17]$. The average compliance, and the proportion of individuals considered compliant in this study were similar for both sexes, indicating no association between compliance and sex [3,5,6,16-18].

The highest incidence of the disease occurred in the 29 to 49 year age group, agreeing with nationwide data [19]. The individuals in this age group are at their most active period of life, both sexually and professionally, but AIDS can be a factor of exclusion of the individual from the work market, and could lead to early retirement.

The average age of the patients in this study was similar to those found by other researchers $[4,17,20]$. As found in other studies, the compliance levels did not appear to differ among the age groups [4-6,17,21]. Some studies have shown how the patient's socialeconomic characteristics affect compliance with antiretroviral medication [2,3]. Most of the patients in this study did not have a steady or permanent partner. The stigma of the disease tends to remove them from society, and leads to difficulties in their relationships [22]. Those who looked for companionship said that it was possible to find only among those with the same condition, as they had similar problems. Some patients did not inform their own families. They concealed the medicines and consumed them in secret, affecting of course the compliance of treatment. Some mentioned difficulties, such as presenting themselves for treatment at the clinic on a regular monthly schedule, since they had not advised employers of their condition, in fear of losing their jobs. However, compliance levels did not appear to be affected by employment, as the proportion was similar for the employed and unemployed.

The degree of schooling can influence the level of compliance, as it affects comprehension of the 
Table 1. Descriptive statistics of the variables: age, time since diagnosis, duration of treatment, number of hospitalizations, number of drugs prescribed, number of drugs in use, compliance, from the 139 interviews of AIDS patients. University Hospital, Campo Grande-MS, 1999/2000

\begin{tabular}{lccccc}
\hline Variable & Average & Median & SD & \multicolumn{2}{c}{ Range } \\
\hline Age (years) & 36.1 & 34 & 8.2 & 19 & 65 \\
Time since diagnosis (years) & 3.5 & 3 & 2.5 & 0.3 & 12.6 \\
Duration of treatment (years) & 2 & 1.9 & 1.5 & 0 & 6.7 \\
Number of hospitalizations & 0.7 & 0 & 1 & 0 & 5 \\
Number of drugs prescribed & 3.7 & 3 & 1.7 & 1 & 10 \\
Number of drugs in use & 2.9 & 3 & 1.6 & 0 & 10 \\
Compliance (\%) & 75.8 & 88 & 31.8 & 0 & 100 \\
\hline
\end{tabular}

SD: standard deviation.

Table 2. Descriptive statistics of the variables: age, time since diagnosis, duration of treatment, number of hospitalizations, number of drugs prescribed, number of drugs in use, and compliance, according to sex (male $=94$; female $=45$ ) of patients with AIDS. University Hospital. Campo Grande-MS, 1999/2000

\begin{tabular}{|c|c|c|c|c|c|c|c|c|c|c|}
\hline \multirow[b]{2}{*}{ Variable } & \multicolumn{2}{|c|}{ Mean } & \multicolumn{2}{|c|}{ Median } & \multicolumn{2}{|c|}{ SD } & \multicolumn{2}{|c|}{ Min. } & \multicolumn{2}{|c|}{ Max. } \\
\hline & $\mathbf{M}$ & $\mathbf{F}$ & $\mathbf{M}$ & $\mathbf{F}$ & $\mathbf{M}$ & $\mathbf{F}$ & $\mathbf{M}$ & F & $\mathbf{M}$ & $\mathbf{F}$ \\
\hline Age (years) & 36.9 & 34.5 & 36 & 33 & 8.3 & 7.9 & 19 & 21 & 65 & 56 \\
\hline $\begin{array}{l}\text { Time since diagnosis } \\
\text { (years) }\end{array}$ & 3.5 & 3.5 & 2.9 & 3 & 2.6 & 2.1 & 0.3 & 0.5 & 12.6 & 8.3 \\
\hline $\begin{array}{l}\text { Duration of treatment } \\
\text { (years) }\end{array}$ & 1.9 & 2 & 1.6 & 2 & 1.6 & 1.3 & 0 & 0.3 & 6.7 & 5 \\
\hline $\begin{array}{l}\text { Number of } \\
\text { hospitalizations }\end{array}$ & 0.6 & 0.8 & 0 & 0 & 0.9 & 1.1 & 0 & 0 & 4 & 5 \\
\hline $\begin{array}{l}\text { Number of drugs } \\
\text { prescribed }\end{array}$ & 3.8 & 3.5 & 3 & 3 & 1.7 & 1.8 & 2 & 1 & 10 & 9 \\
\hline Number of drugs in use & 3 & 2.8 & 3 & 2 & 1.6 & 1.8 & 0 & 0 & 10 & 8 \\
\hline Compliance (\%) & 77.2 & 73 & 89 & 86 & 31.1 & 33.6 & 0 & 0 & 100 & 100 \\
\hline
\end{tabular}

M: male; F: female; SD: standard deviation. 
Table 3. Distribution of the 139 Individuals with AIDS, according to level of schooling and compliance. University Hospital. Campo Grande-MS, 1999/2000

\begin{tabular}{lllll}
\hline & & \multicolumn{2}{c}{ Compliance* } & \\
\cline { 3 - 4 } Schooling & & No & Yes & Total \\
\hline Illiterate & $\begin{array}{l}\text { Frequency } \\
(\%)\end{array}$ & 05 & 05 & $10(7.2 \%)$ \\
& Frequency & 50 & 50 & \\
Basic & $(\%)$ & 40 & 42 & $82(59 \%)$ \\
& Frequency & 07 & 51.2 & $47(33.8 \%)$ \\
High school & $(\%)$ & 14.9 & 40 & 139 \\
Total & Frequency & 52 & 85.1 & 100 \\
\hline
\end{tabular}

*Compliance was stipulated as at least $80 \%$ of the medication consumed during the previous week.

Table 4. Distribution of 139 Individuals with AIDS, according to sex and compliance. University Hospital, Campo Grande-MS, 1999/2000

\begin{tabular}{|c|c|c|c|c|c|}
\hline & \multicolumn{4}{|c|}{ Individuals } & \multirow[b]{3}{*}{ Total } \\
\hline & \multicolumn{2}{|c|}{$\begin{array}{l}\text { Compliant } \\
(\geq \mathbf{8 0 \%})\end{array}$} & \multicolumn{2}{|c|}{$\begin{array}{c}\text { Non-compliant } \\
(<\mathbf{8 0} \%)\end{array}$} & \\
\hline & Frequency & $(\%)$ & Frequency & $(\%)$ & \\
\hline Male & 60 & 64 & 34 & 36 & 94 \\
\hline Female & 27 & 60 & 18 & 40 & 45 \\
\hline Total & 87 & 63 & 52 & 37 & 139 \\
\hline
\end{tabular}


explanations presented by the health agents. Uninformed patients may use the medication incorrectly $[14,23]$. In some studies there were no significant differences in compliance were found among the individuals with different levels of schooling $[4,16]$. However, in other studies schooling levels affected compliance [7,17]. In our study, compliance was higher among the better schooled.

The fact that an individual infected by HIV can remain asymptomatic for long periods, could lower the motivation for compliance to treatment $[1,24]$. In our study, no correlation was observed between compliance and time since diagnosis, and between the latter and the duration of treatment. However, some researchers observed that there was less compliance initially, as the patients had to adapt their life styles to incorporate the treatment program $[1,5]$.

The perception that the patient has of his, or her, disease can influence the compliance to antiretroviral therapy $[1,3]$. Hospitalization could emphasize the seriousness of the case, thereby encouraging compliance. We did not find any correlation between compliance and the number of hospitalizations, however most of the patients had never been hospitalized, and many reported a short time since diagnosis.

An extensive and complex therapeutic regimen can influence compliance, as it makes it more difficult to adapt the treatment to the daily activities of the patient $[3,7,21,23]$. On the other hand, this could encourage compliance [4]. The gravity of the clinical and laboratory picture could explain this tendency. We found a small correlation between compliance and the number of drugs used, which could mean that increasing the number of drugs also increases compliance.

Loss or omission, of drugs can occur, and seems to be associated with therapeutic regimens of long duration and high complexity. Some patients mentioned omitting dosages in order to "give the body a rest"; others claimed loss of dosages because of lack of adaptation of the treatment regimen to their daily routine. Most of the patients had misplaced at least one dose of antiretroviral medicine during the week prior to the interview.
Several studies have reported that forgetfulness is one of the main causes of non-compliance [12$14,20,23]$. In our study, forgetfulness was also the principal reason given for non-compliance.

We found a mean compliance and proportion of compliant patients similar to that observed in other studies [4-6,17].

\section{Conclusions}

The prevalence of compliance, in this study, was lower than the stipulated limit. The main reason for noncompliance was forgetfulness. Men and women had similar rates of compliance, while schooling level had a strong positive influence on compliance. The reasons given by the patients to justify the lapses in compliance accentuate the necessity of efforts on the part of the health teams to promote programs to recuperate the therapeutic regimens, employing methods adequate to the characteristics of this population.

\section{References}

1. Williams A. Antiretroviral therapy: factors associated with adherence. J Assoc Nurses Aids Care 1997;8:18-23.

2. ONUSIDA. A epidemia de SIDA: situación en diciembre de 1999.[Online] Genebra 2000. [Cited 23 mar 2000]. Available from: http//www.unaids.org/publications/ documents/epidemiology/suveillance/wad1999/ Una99s53.doc.

3. Ickovics J.R., Meisler A.W. Adherence in AIDS. Clinical Trials: a framework for clinical research and clinical care. J Clin Epidemiol 1997;50:385-91.

4. Singh N., Squier C., Sivek C. et al. Determinants of compliance with antiretroviral therapy in patients with human immunodeficiency virus: prospective assessment with implications for enhancing compliance. AIDS Care 1996;8:261-9.

5. López-Suárez A., Fernandez-Gutierrez A., Pérez-Gusmán E., Girón-González J.A. Adherence to the antiretroviral treatment in asymptomatic $\mathrm{HIV}$-infected patients. AIDS 1998; $12: 685-6$.

6. Rodriguez-Rosado R., Jiménez-Nácher I., Soriano V., Antón P., González-Lahoz J. Virological failure and adherence to antiretroviral therapy in HIV-infected patients. AIDS 1998; 12:1112-3. 
7. Sincok V.M., Figueiredo R.M., Colombrini R.C., et al. Dificuldades referidas por pacientes com AIDS na adesão ao tratamento com antiretrovirais. Braz J Infect Dis 1999;3:S60.

8. Pires V.R.S., Santana A.C.L., Monteiro M.D.M. Aderência ao tratamento com antiretrovirais: experiência em Maceió -AL. Braz J Infect Dis 1999;3(Suppl 2):S65.

9. Homedes N., Ugalde A. Qué sabemos del cumplimento de los tratamientos médicos en el tercer mundo? Bol Sanit Panam 1994;116:491-517.

10. Zar J.H. Biostatistical Analysis. 4th ed. Upper Saddle River: Prentice Hall 1999, 663p.

11. Soares J.F., Siqueira A.L. Introdução à estatística médica. Belo Horizonte: Departamento de Estatística-UFMG, 1999, 300p.

12. Lorenzen T., Stoehr A., Weitner L., et al. Compliance with antiretroviral multidrug therapy in HIV- infected patients and reasons for non-compliance. In: Abstracts of the $12^{\text {th }}$ World AIDS Conference, 1998. Geneva, 1998. [Accessed 2000 May 15]. Available from: http:// www.abst...

AIDS.cfm?ViewAbstract $=14123 \&$ searchon=adherence\& ItemsPerPage $=$.

13. Weidle P.J., Ganea C.E., Ernst J., et al. Multiple reasons for nonadherence to antiretroviral medications in an inner-city minority population: Need for a multifaceted approach to improve adherence. In: Abstracts of the $12^{\text {th }}$ World AIDS Conference, 1998. Geneva, 1998. [Accessed 2000 May 15]. Available from: http:// www.abstracts-on-line.com/scripts/abstracts/aids/ AIDS.cfm/89614262

14. Paiva V., Santos N., Ventura-Filipe E.M., et al. Compliance with reverse transcription inhibitors or combination therapy among HIV+ Women in São Paulo Brazil. In: Abstracts of the $12^{\text {th }}$ World AIDS Conference, 1998. Geneva, 1998. [Accessed 2000 May 15]. Available from: http://www.abst.../AIDS.cfm?ViewAbstract=14151 \&searchon $=$ adherence $\&$ ItemsPerPage $=$

15. Quirk J., Wilks J. Patient compliance on combination HIV antiretroviral therapies. In: Abstracts of the $12^{\text {th }}$ World AIDS Conference, 1998. Geneva, 1998. [Accessed 2000 May 15]. Available from: http://www.abst.../ AIDS.cfm? ViewAbstract $=14136 \&$ searchon $=$ adherence \&ItemsPerPage $=$

16. Klosinski L. E., Brooks R.N.A. Predictors of nonadherence to HIV combination therapies. In: Abstracts of the $12^{\text {th }}$ World AIDS Conference, 1998. Geneva, 1998. [Accessed 2000 May 15]. Available from: http:// www.abstracts-on-line.com/scripts/ abstracts/ aids/ AIDS.cfm/89614262

17. Nemes M.I.B., De Souza M.F.M., Kalichman A.O. et al. Avaliação da aderência ao tratamento por antiretrovirais de usuários de ambulatórios do sistema público de assistência à Aids no Estado de São Paulo: Prevalência da aderência e fatores associados. [Online] Brasília, 1999. [Accessed 16 Nov 1999]. Available from: http://www.aids.gov.br/ planejamento/ pesquisaadesão.htm

18. Rocha M.D.C., De Lucca M.A.C., Garcia R.A. et al. A não aderência ao tratamento com antiretrovirais. Braz J Infect Dis 1999;3(Suppl 2): S58.

19. BRASIL. Ministério da Saúde/CN-DST/Aids. Bol Epidemiol-Aids 1999;12(4):25.

20. Arabe J., Rubini N.P.M., Rodrigues A.C.A. et al. Factors which influence adherence to the use of protease inhibitors. In: Abstracts of the $12^{\text {th }}$ World AIDS Conference, 1998. Geneva, 1998. [Cited 2000 May 15]. Available from: http://www.abst.../AIDS.cfm? ViewAbstract $=14156 \&$ searchon $=$ adherence\&ItemsPerPage=

21. Mehta S., Moore R.D, Graham N.M.H. Potential factors affecting adherence with HIV therapy. AIDS 1997; 11: 1665-70.

22. Flaskerud, J.H. Aspectos Psicossociais e Neuropsiquiátricos. In: _. . AIDS/Infecção pelo HIV. Rio de Janeiro: MEDSI, 1992.

23. Bachiller P., Rodríguez F., Liceaga A.G. et al. Adherence to antiretroviral therapy in HIV-infected patients. In: Abstracts of the $12^{\text {th }}$ World AIDS Conference, 1998. Geneva, 1998. [Accessed 2000 May 15]. Available from: http://www.abst.../AIDS.cfm? ViewAbstract $=$ $14144 \&$ searchon $=$ adherence $\&$ ItemsPerPage $=$

24. Eldred, L. Adherence in the era of protease inhibitors. Hopkins HIV Report [serial online], 1997. [Accessed 2000 May 15]. Available from: http://www.hopkinsaids.edu/publications/ report/jul97 4.html. 